\title{
Oxidation rate of sulfite in water and its bearing on the origin of sulfate in meteoric precipitation
}

\author{
Shizuo TsunogaI \\ Department of Chemistry, Faculty of Fisheries \\ Hokkaido University, Hakodate, Japan
}

(Received June 1, 1971)

\begin{abstract}
The oxidation rate of sulfite was determined in its dilute solution. The reaction is substantially of the first order and the rate is much accelerated by the presence of small amounts of heavy metals such as iron, copper and manganese. The half-life time of sulfite in the natural rain water is more than a few hours. The observed concentration of sulfite in rain water is nil or much smaller than that of sulfate. Thus, the anthropogenic sulfur is removed from the atmosphere after the oxidation to sulfate in air or in cloud droplets. The residence time of aerosol sulfur of anthropogenic origin and the mean-life time of sulfur dioxide for the oxidation are estimated to be 10 days and $30 \mathrm{hrs}$, respectively, from the concentrations of sulfate and ${ }^{210} \mathrm{~Pb}$ in precipitation. It is inferred from the experiments and the observations that excess sulfate in meteoric precipitation is essentially of anthropogenic origin.
\end{abstract}

\section{INTRODUCTION}

The residence time of a substance in the atmosphere is the most useful index for discussing its circulation through the atmosphere and the earth's surface. According to the Junge's observation in the United States (JungE, 1960), the major source of the atmospheric sulfur compounds is anthropogenic sulfur. The sulfur is emitted to the atmosphere in the forms of oxide, mainly sulfur dioxide. The residence time of anthropogenic sulfur can be divided into two parts. One is the lifetime of gaseous sulfur starting from its generation by the combustion and ending with being captured by cloud drops or by aerosol after being oxidized to sulfate. The other is the residence time of sulfate in aerosol, in which all the chemical constituents have the same residence time. The latter can be estimated by radioactive tracers such as radon daughter nuclides (BURTON and STEWART, 1960; BLIFFORD et al., 1952) or cosmic ray produced nuclides (LAL, 1959).

The former can be hardly determined in the laboratory, because the condition is different from natural one. Laboratory experiments, however, can determine the oxidation rate of sulfur dioxide in the pure air with or without irradiation of sunlight. The most difficult point in this sort of experiments is to reproduce the interaction 
between sulfur dioxide and rain drops. JUNGE and RYAN (1958) suggested that the role of ammonia is important in the dissolution of sulfur dioxide into rain. They, however, used high concentration of sulfur dioxide in the air (5-15 ppm) in their experiments. Soon after the start of bubbling the air into water, the water was supposed to be saturated with sulfur dioxide. That is to say, the rate-determining step of the dissolution of sulfur dioxide is not the interaction at the air-water interface but the dissociation process of sulfurous acid, which is accelerated by neutralization such as the absorption of ammonia or by the oxidation of sulfite to sulfate in water. The condition of their experiments is far from the natural one. Therefore, I intend to determine the oxidation rate of sulfite in the dilute solution of sulfite and to discuss the mechanism of oxidation and the role of the oxidation rate in the transport of sulfur compounds through the atmosphere.

\section{EXPERIMENTAL AND RESULTS}

Determinations of sulfite and sulfate in water

The method by WEST and GAEKE (1956) was initially used for the analysis of sulfite in water. Later, EDTA was used as a preserving reagent of sulfite in the place of mercuric chloride. This improvement is based on the result described later. The procedure is as follows. Immediately after the sampling, an EDTA 4 Na solution was

Table 1. Sulfite concentration in rain water over Hakodate

\begin{tabular}{|c|c|c|c|}
\hline \multicolumn{2}{|l|}{ Date } & \multirow{2}{*}{$\begin{array}{c}\begin{array}{c}\mathrm{SO}_{3}^{=}-\mathrm{S} \\
\mathrm{ppb}\end{array} \\
28\end{array}$} & \multirow[t]{2}{*}{$\begin{array}{c}\mathrm{SO}_{4}^{=}-\mathrm{S} \\
\mathrm{ppm}\end{array}$} \\
\hline July $18, ' 66$ & $15: 30$ & & \\
\hline (Cold front) & 33 & 10 & \multirow{6}{*}{1.8} \\
\hline & 36 & 10 & \\
\hline & 39 & 0 & \\
\hline & 42 & 0 & \\
\hline & 45 & $8)$ & \\
\hline & 48 & 0 & \\
\hline June $13, ' 67$ & $13: 15$ & $9)$ & \multirow{3}{*}{0.9} \\
\hline & 19 & 0 & \\
\hline & 42 & $0 J$ & \\
\hline June 18, '67 & $13: 50$ & 195 & 3.8 \\
\hline Aug. 10, '67 & $9: 30$ & $2)$ & \multirow{8}{*}{0.5} \\
\hline (Warm front) & 40 & 56 & \\
\hline & 50 & 0 & \\
\hline & $10: 09$ & 0 & \\
\hline & 21 & 0 & \\
\hline & 30 & 0 & \\
\hline & 50 & 8 & \\
\hline & $11: 10$ & 0 & \\
\hline Aug. 12, '67 & $11: 00$ & 67 & 1.5 \\
\hline Sept. $16, ' 67$ & $9: 27$ & 28 & 2.1 \\
\hline
\end{tabular}


added to the sample to make the concentration $0.1 \mathrm{mM}$. Within a day, $1 \mathrm{ml}$ of $0.04 \%$ $p$-rosaniline solution in $0.07 \mathrm{~N}$ hydrochloric acid and $1 \mathrm{ml}$ of $0.2 \%$ formaldehyde solution were added to a $10 \mathrm{ml}$-aliquot of the sample. The developed color was measured at $548 \mathrm{~nm}$ after $30 \mathrm{~min}$. The interference by nitrite, if any, can be previously removed by the addition of $1 \mathrm{ml}$ of $6 \%$ sulfamic acid solution to $25 \mathrm{ml}$ of the sample. The concentration of sulfate was determined by the method of IWASAKI et al. (1957).

\section{Sulfite in meteoric precipitation}

The rain water samples were collected on the Hakodate campus of Hokkaido University. Table 1 shows a few examples of the analytical results. Sulfite was occasionally observed in the rain water samples. Among 18 rainfalls, 5 rainfalls contained sulfite more than a detection limit of $0.005 \mathrm{ppm} \mathrm{S}$ and the maximum concentration was $0.19 \mathrm{ppm} \mathrm{S}$. The cause of its presence is not so clear, but the local anthropogenic source may contribute because there is a factory producing fertilizers, Nissan Chemical Co. Ltd. which is situated $1.2 \mathrm{~km}$ south-east of the university. Sulfur dioxide and sulfur trioxide are often emitted from the factory.

\section{The oxidation rate of sulfite in solution}

Suitable amounts of sulfite were added to $200 \mathrm{ml}$ of rain water samples or solutions which contain various cations or EDTA. The solutions were allowed to stand in a thermostat, and occasionally a $10 \mathrm{ml}$-aliquot was taken from each solution and the concentration of sulfite was determined by the method described above. The

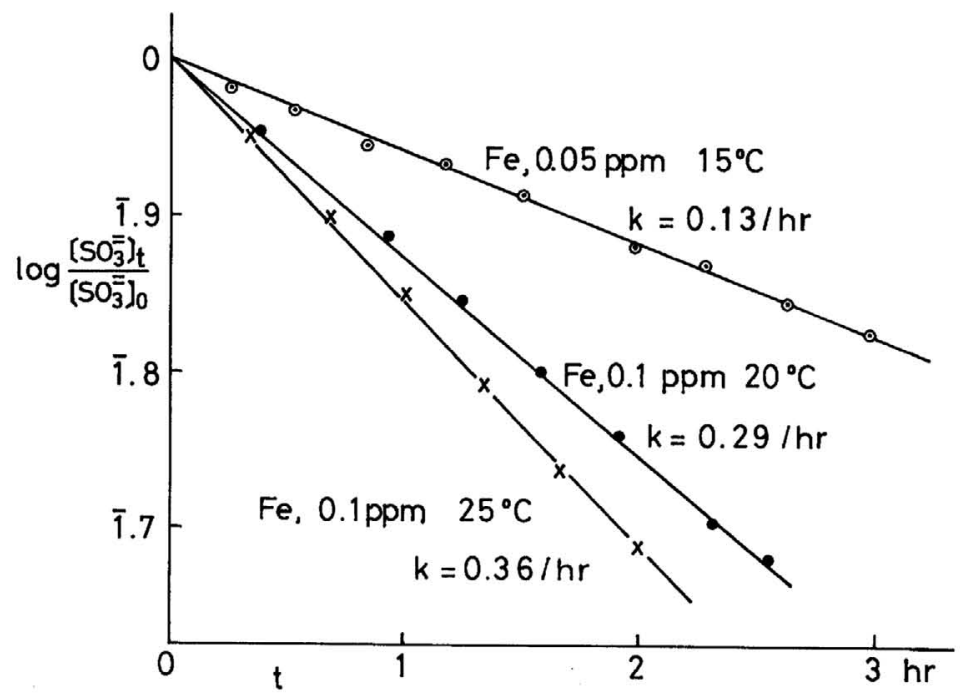

Fig.1. Oxidation of sulfite in solution. 
initial concentrations of sulfite and $\mathrm{pH}$ of the solutions were $0.5-0.7 \mathrm{ppm}$ and about 7 , respectively. When plotted against time, the logarithm of the sulfite concentration decreases linearly as shown in Fig.1. This means that the oxidation of sulfite is substantially regarded as a first-order reaction. The rate constants are determined for the various solutions as given in Table 2.

Table 2. Oxidation rates of sulfite in solutions

\begin{tabular}{|c|c|c|c|}
\hline \multicolumn{2}{|c|}{ Solution ${ }^{1)}$} & \multirow{2}{*}{$\begin{array}{c}\text { Water temp. } \\
{ }^{\circ} \mathrm{C}\end{array}$} & \multirow{2}{*}{$\begin{array}{c}\text { Rate constant } \\
\mathrm{hr}^{-1}\end{array}$} \\
\hline $\begin{array}{l}\text { Metal } \\
\text { ppm }\end{array}$ & $\begin{array}{c}\text { EDTA } \\
\text { mM }\end{array}$ & & \\
\hline \multicolumn{2}{|c|}{ Deionized water } & $20-25$ & 0.009 \\
\hline - & 0.1 & $20-25$ & 0.0002 \\
\hline $\mathrm{Fe}, \quad 1$ & - & 25 & $>4.9$ \\
\hline $\mathrm{Fe}, \quad 1$ & 0.1 & $20-25$ & 0.008 \\
\hline $\mathrm{Fe}, \quad 0.1$ & - & 25 & 0.36 \\
\hline $\mathrm{Fe}, \quad 0.1$ & - . & 20 & 0.29 \\
\hline $\mathrm{Fe}, \quad 0.05$ & - & 15 & 0.13 \\
\hline $\mathrm{Cu}, \quad 0.1$ & - & 20 & 0.27 \\
\hline $\mathrm{Mn}, 0.1$ & - & 20 & 0.12 \\
\hline $\mathrm{Al}, \quad 0.1$ & - & 20 & 0.086 \\
\hline Co, 0.1 & - & 20 & 0.057 \\
\hline Rain, June 1 & $8, ' 67$ & 20 & 0.068 \\
\hline
\end{tabular}

1) Sodium sulfite was dissolved in the deionized water containing some metal salts and EDTA $4 \mathrm{Na}$ salt. Initial concentrations were $0.5-0.8 \mathrm{ppm}$ as sulfite-sulfur.

\section{Discussion}

The mechanism of oxidation of sulfite in water

In dilute solution, sulfite is slowly oxidized to sulfate. As shown in Table 2, the oxidation was accelerated by cations, especially transition metals such as iron, copper and manganese. The oxidation rate is 30 times larger in the solution containing $0.1 \mathrm{ppm}$ of ferric ions than in deionized water where the half-life time of sulfite is about 80 hours. Iron is the most effective among the metal cations examined in this experiment. In the presence of ferric ions more than $1 \mathrm{ppm}$, the rate is too fast to measure it precisely. The effect of the cations can be removed by using a masking agent such as EDTA. As shown in Table 2, $0.1 \mathrm{mM}$ solution of EDTA can nearly eliminate the effect of $1 \mathrm{ppm}$ of iron. These facts certify that the heavy metal ions act as catalysts in the oxidation of sulfite. This idea has been proposed by JUNGE and RYAN (1958).

In the natural rain, the half-life time of sulfite was about 10 hours and the oxidation rate corresponds to the presence of $0.0 \mathrm{nppm}$ of heavy metals. This seems to 
be compatible with the actual concentration of these metals in rain (SUGAWARA, 1964).

The oxidation rate depends on the water temperature as shown in Fig.1. The activation energy for the oxidation is calculated as $3.6 \mathrm{kcal} / \mathrm{mole}$ in the solution containing $0.1 \mathrm{ppm}$ iron.

As shown by this experiment, the EDTA solution can be used as a preserving reagent of sulfite instead of mercuric chloride used by WEST and GAEKE (1956) for the determination of sulfur dioxide in air. Sulfur dioxide is absorbed more effectively in the EDTA solution than in the solution of mercuric chloride because the EDTA solution is more alkaline. The analytical method for sulfur dioxide in the air will be shown elsewhere.

\section{Origin of sulfate in meteoric precipitation}

If sulfate in rain water originated from sulfur dioxide dissolved into falling rain drops in the atmosphere, sulfite would be detected in the rain water collected soon after the rainfall owing to its slow oxidation rate. Although sulfite was sometimes found in rain over Hakodate, its concentration was much smaller than that of sulfate. Thus, besides sea salt sulfate, sulfate in rain does not come from the immediate dissolution of sulfur dioxide into falling rain drops but may come from sulfate in aerosols which has been formed by oxidation in the air or in the cloud droplets prior to incorporation into the rain drops. This implies that the residence time of anthropogenic sulfur in the atmosphere consists of the residence time of aerosol sulfate and the mean-life time of sulfur dioxide in the atmosphere with respect to its oxidation to sulfate.

The mean-life time of sulfur dioxide in the natural air has been hardly determined. GERHARD and Johnstone (1955) have found that sulfur dioxide in the air is photochemically oxidized by the irradiation of sunlight, and estimated the half-life time of sulfur dioxide as 15 to 30 days. The half-life time of sulfur dioxide in the polluted air was determined as 11 hours by MEEThaM (1950) and $20 \mathrm{~min}$ to $3 \mathrm{hrs}$ by WEBER (1970), respectively. JUNGE (1960) recalculated the time as 4 days from the data by MeEtham. We do not have any reliable mean-life time of sulfur dioxide in the atmosphere.

The residence time of aerosole sulfur and gaseous sulfur can be roughly estimated by the following way. It is advantageous for the estimation to compare the sulfur dioxide-sulfate system with the system of ${ }^{222} \mathrm{Rn}-{ }^{210} \mathrm{~Pb}$ in the atmosphere. Radon is produced from ${ }^{226} \mathrm{Ra}$ in the ground and diffuses into the atmosphere. Afterwards, the radon changes into heavy metals such as ${ }^{210} \mathrm{~Pb}$. The heavy metals are attached to natural aerosols soon after their formation. The mean-life of ${ }^{222} \mathrm{Rn}$ is 5.5 days and the residence time of the aerosols is about 20 days (BURTON and STEWART, 1960). This system is similar to that of gaseous sulfur dioxide and aerosol sulfate. The situation is schematically shown in Fig. 2 and quantitatively discussed as follows. 


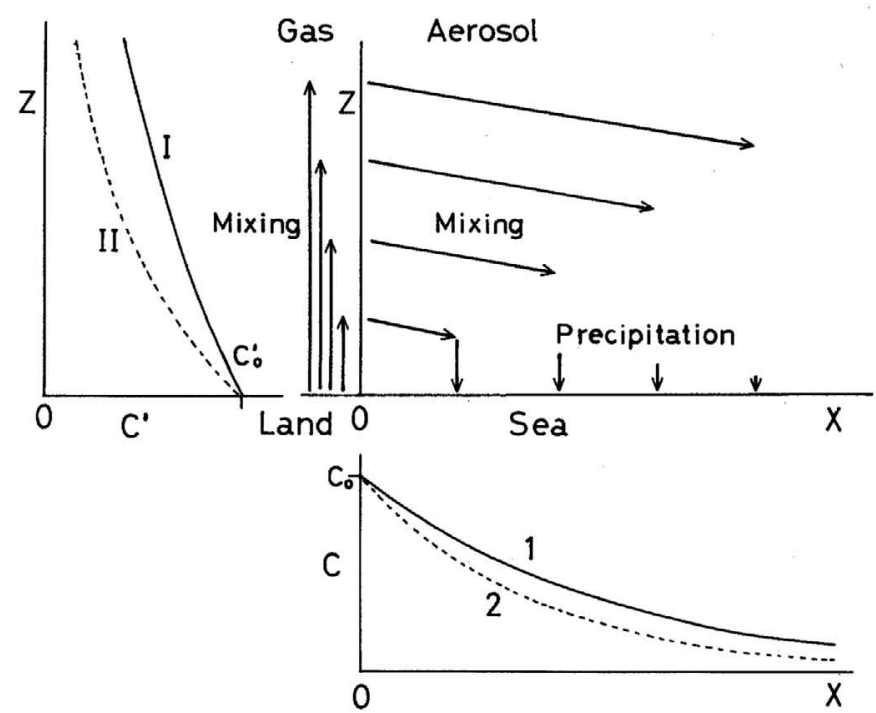

Fig.2. Schematic diagram of transport of a constituent produced from its precursor in the atmosphere. $X$, distance from the source area; $Z$, altitude; $C$, concentration of the constituent in precipitation or amount in a unit air column; and $C_{0}$, that in the source area; $C^{\prime}$, concentration of the gaseous precursor in the atmosphere, and $C_{0}^{\prime}$, that on the ground surface. The curves of solid lines, 1 and I show $C$ and $C^{\prime}$ of a constituent of longer residence time in the atmosphere and the curves of dotted lines, 2 and II show those of shorter residence time.

A chemical constituent in the atmosphere aerosol is assumed to be transported from the source area by the turbulent mixing with a constant austausch coefficient and to be removed proportionally to its amount in a given air column. The reciprocal of the proportionality constant $(k)$ is the residence time $(T)$ of aerosol bearing the constituent. The variation of the amount of the constituent $(C)$ with time $(t)$ in a vertical air column apart $X$ from the source area is given by

$$
\frac{\mathrm{d} C}{\mathrm{~d} t}=A \frac{\mathrm{d}^{2} C}{\mathrm{~d} X^{2}}-k C
$$

where $A$ is the horizontal austausch coefficient. This gives under the steady state condition,

$$
C_{x}=C_{0} \exp (-\sqrt{k / A} X)
$$

where $C_{0}$ is the amount in the source area or in the reference area. In the natural condition, we can hardly get the point source of ${ }^{210} \mathrm{~Pb}$ or anthropogenic sulfur. Then, $C_{0}$ is substituted by the mean concentration of a constituent in a vertical air column 
over the land and $C_{x}$ by that over the ocean. The $C_{x} / C_{0}$ ratio is assumed to be equal to the concentration ratio of the constituent in precipitations over the land and the ocean. Mean concentrations of sulfate and ${ }^{210} \mathrm{~Pb}$ in precipitations are estimated below. Most of sulfate in rain over the sea comes from sea salts. The anthropogenic sulfur is comprised in excess sulfate, i.e., the difference between sulfate observed and sea salt sulfate calculated from chloride content in rain. JUNGE and WERBY (1958) have taken $2.2 \mathrm{ppm}$ as the average of excess sulfate for the whole earth from the data observed in rain over the U. S. A. MIYAKE and TsunOGaI (1965) obtained nearly the same value in rain over the rural area of Japan. The excess sulfate over the sea is much smaller than that over the land. ERIKSSON (1957) obtained $0.48 \mathrm{ppm}$ for rain over Hawaii. Oceanic rain over Hachijojima Island contained 0.1 to $0.3 \mathrm{ppm}$ of excess sulfate (Miyake and TsunogaI, 1965). Murozumi et al. (1969) compiled the data on the chemical composition of Greenland and Antarctic ices which showed $0.2 \mathrm{ppm}$ for the mean excess sulfate, but they have considered that most of the excess sulfate may have been derived from the experimental error. The mean values, therefore, are estimated to be $2 \mathrm{ppm}$ and $0.2 \mathrm{ppm}$ for the excess sulfate in rains over the land and over the ocean, respectively.

The mean concentration of ${ }^{210} \mathrm{~Pb}$ in rain over the land was reported as $5 \mathrm{dpm} / 1$ by Burton and Stewart (1960). MiYake and Kubota (1967) found 5 to $7 \mathrm{dpm} / 1$ of ${ }^{210} \mathrm{~Pb}$ in the monthly collected rain in Tokyo. KING et al. (1956) observed 2.0 and $0.4 \mathrm{dpm} / 1$ of ${ }^{210} \mathrm{Bi}$ for rains over Hawaii and Samoa, respectively. TsuNOGAI and NozAKI (unpublished) measured the concentration of ${ }^{210} \mathrm{~Pb}$ in rain collected on board in the mid-Pacific, which was 0.7 to $2.0 \mathrm{dpm} / 1$. It may be said from these data that the mean ${ }^{210} \mathrm{~Pb}$ contents are $5 \mathrm{dpm} / 1$ and $1 \mathrm{dpm} / 1$ in rains over the land and over the sea, respectively.

The equation (2) is written for ${ }^{210} \mathrm{~Pb}$ and sulfate by using suffixes 1 and 2 , respectively, as

and

$$
1 / 5=\exp \left(-\sqrt{k_{1} / A} X\right)
$$

Therefore,

$$
0.2 / 2=\exp \left(-\sqrt{k_{2} / A} X\right)
$$

$$
k_{1} / k_{2}=T_{2} / T_{1}=[\ln (1 / 5) / \ln (0.2 / 2)]^{2}=0.5
$$

Since the residence time of aerosol ${ }^{210} \mathrm{~Pb}$ in the atmosphere is about 20 days, the residence time of aerosol sulfate turns out to be 10 days. The residence time of the aerosol bearing sulfate is shorter than that bearing ${ }^{210} \mathrm{~Pb}$. This may be caused by the different vertical distribution of aerosols containing these constituents in the source area, because physical and chemical natures of these aerosols seem to be not so different from each other. The vertical distribution of a constituent in the source area depends on the mean-life time of its precursor in a gaseous form in the atmosphere. If aerosols fall with a constant velocity including the effect of rainfall, the residence 
time of the aerosols bearing the constituent is proportional to the mean altitude of the vertical production rate of the constituent from its precursor. The equation of the production rate is given by the same form as the vertical distribution of the precursor in the source area. If $D$, the vertical austausch coefficient, is assumed to be constant for simplicity, the vertical distribution is given as the solution of the following equation,

$$
\frac{\mathrm{d} C^{\prime}}{\mathrm{d} t}=D \frac{\mathrm{d}^{2} C^{\prime}}{\mathrm{d} Z^{2}}-\lambda C^{\prime}=0
$$

where $C^{\prime}$ is the concentration of the precursor, $\lambda$ is its decay constant and $Z$ is the altitude. The reciprocal of $\lambda$ is the mean-life of the precursor. Then, the solution is obtained as

$$
C^{\prime}=C_{0}^{\prime} \exp (-\sqrt{\lambda / D} Z)
$$

where $C^{\prime}{ }_{0}$ is the concentration at the ground surface. The mean altitude $(h)$ of the distribution is given by

$$
h=\frac{\int_{0}^{\ell} Z C^{\prime} c Z}{\int_{0}^{\ell} C^{\prime} \mathrm{d} Z} \div \frac{\int_{0}^{\infty} Z C^{\prime}{ }_{0} \exp (-\sqrt{\lambda / D} Z) \mathrm{d} Z}{\int_{0}^{\infty} C^{\prime}{ }_{0} \exp (-\sqrt{\lambda / D} Z) \mathrm{d} Z}=\sqrt{D / \lambda}
$$

where $\ell$ is the height of the tropopause. The mean-life $\left(\tau_{2}\right)$ of sulfur dioxide can be obtained by the following relations,

$$
T_{1} / T_{2}=h_{1} / h_{2}=\sqrt{D / \lambda_{1}} / \sqrt{D / \lambda_{2}}=\sqrt{\lambda_{2} / \lambda_{1}}=\sqrt{\tau_{1} / \tau_{2}}
$$

As the ratio, $T_{1} / T_{2}$ is 2 and $\tau_{1}$ is 5.5 days, the mean-life of sulfur dioxide for the oxidation turns out to be $30 \mathrm{hrs}$. The overall residence time of anthropogenic sulfur in the atmosphere is estimated to be 11 days. This is shorter than that of ammonia (30 days, TsunOGaI and IKEUCHI, 1968), but much longer than that of sea salt particles (1 to 3 days, Junge, 1963).

The sulfur of land origin is expected to be distributed all over the world by the turbulent mixing of the air. It has been found that a part of ${ }^{222} \mathrm{Rn}$ exhaled from the earth's surface is brought into the stratosphere (FEELY and SEITZ, 1970). The mean-life of sulfur dioxide seems to be long enough to make possible the presence of sulfur in the stratosphere. JUNGE and MANSON (1961) studied the chemical composition of the stratospheric aerosols and found that sulfur is the dominant element. They have concluded that the stratospheric aerosols are mainly made up of the particles of ammonium sulfate or ammonium bisulfate. As shown in Table 3, contents of sulfate, ${ }^{210} \mathrm{~Pb}$ and $\beta$ radioactivity were determined for snow samples over the coast of the Japan Sea where the ground was covered by snow. The ${ }^{210} \mathrm{~Pb}$ content was determined by the method of MIYAKE and KuBOTA (1965) and the total $\beta$ activity of evaporation residue was counted by an end-window type G. M. counter. Much amount of excess sulfate was brought to Japan together with the yellow sands as well as ${ }^{210} \mathrm{~Pb}$ and total $\beta$ activity which was of the stratospheric origin at that time. In 
Table 3. Sulfate, ${ }^{210} \mathrm{~Pb}$ and total $\beta$ activity observed in snow over the coast of the Japan Sea

\begin{tabular}{|c|c|c|c|c|c|c|c|}
\hline \multicolumn{8}{|c|}{ a) Hitotsuya, $6 \mathrm{~km}$ from the Japan } \\
\hline $\begin{array}{c}\text { Date } \\
1966 \\
\end{array}$ & \multirow{2}{*}{$\begin{array}{c}\begin{array}{c}\text { Rainfall } \\
\mathrm{mm}\end{array} \\
6.1\end{array}$} & \multirow{2}{*}{$\begin{array}{c}\begin{array}{c}\text { Residue } \\
\mathrm{g} / \mathrm{m}^{2}\end{array} \\
0.34\end{array}$} & \multirow{2}{*}{$\begin{array}{c}\begin{array}{c}\mathrm{Cl} \\
\mathrm{ppm}\end{array} \\
5.88\end{array}$} & \multirow{2}{*}{$\begin{array}{r}\mathrm{SO}_{4} \\
\mathrm{ppm}\end{array}$} & \multirow{2}{*}{$\begin{array}{c}\begin{array}{c}\mathrm{\delta SO}_{4}{ }^{1)} \\
\mathrm{ppm}\end{array} \\
5.11\end{array}$} & \multirow{2}{*}{$\begin{array}{c}\begin{array}{c}\delta \mathrm{SO}_{4} / \beta \\
\mu \mathrm{g} / \mathrm{cpm}\end{array} \\
181\end{array}$} & \multirow{2}{*}{$\begin{array}{c}\begin{array}{c}\delta \mathrm{SO}_{4} / 210 \\
\mu \mathrm{Pb}\end{array} \\
81\end{array}$} \\
\hline $15-17$ h Feb. $3^{2)}$ & & & & & & & \\
\hline $21-8^{\text {h }}$ Feb. $4^{3)}$ & - & 4.05 & $(209)^{4)}$ & $(77.7)^{4)}$ & $(48.5)^{4)}$ & 63 & - \\
\hline $9-17 \mathrm{~h}$ Feb.4 & 6.4 & 0.84 & 7.60 & 5.99 & 4.93 & 145 & 74 \\
\hline $9-21^{h}$ Feb.5 & 3.0 & 0.24 & 25.6 & 6.55 & 2.98 & 110 & 54 \\
\hline $7-14 \mathrm{~h}$ Feb.6 & 2.6 & 0.097 & 8.98 & 3.30 & 2.05 & 136 & - \\
\hline \multicolumn{8}{|c|}{ b) Shishiku, $15 \mathrm{~km}$ from the Japan Sea and $600 \mathrm{~m}$ above the sea level } \\
\hline Date & Rainfall & Residue & $\mathrm{Cl}$ & $\mathrm{SO}_{4}$ & $\mathrm{SSO}_{4}$ & $\delta \mathrm{SO}_{4} / \beta$ & $\delta \mathrm{SO}_{4} /{ }^{210} \mathrm{~Pb}$ \\
\hline $15-18^{h}$ Feb. $3^{2)}$ & 22.4 & 1.92 & 3.17 & 5.52 & 5.08 & 164 & 119 \\
\hline $21-24$ h Feb. $3^{3)}$ & 6.4 & 12.18 & 80.5 & 33.8 & 22.6 & 70 & 90 \\
\hline $0-8^{\mathrm{h}} \mathrm{Feb} .4^{3)}$ & 1.6 & 4.74 & 136 & 48.8 & 29.8 & 100 & - \\
\hline $9-18^{\mathrm{h}}$ Feb.4 & 13.8 & 1.16 & 5.31 & 4.40 & 3.66 & 115 & 68 \\
\hline $9-20^{h}$ Feb.5 & 6.7 & 0.20 & 9.66 & 3.18 & 1.83 & 141 & 47 \\
\hline $9-15 \mathrm{~h}$ Feb.6 & 6.6 & 0.156 & 6.24 & 2.40 & 1.53 & 115 & - \\
\hline
\end{tabular}

1) Excess sulfate

2) Rain by the cold front

3) "Red snow" containing the yellow sands

4) in the unit of $\mathrm{mg} / \mathrm{m}^{2}$

Table 4. World sulfur budget in the atmosphere in 1964 by MIYAKE and TSUNOGAI (1965)

\begin{tabular}{|c|c|c|c|c|}
\hline \multicolumn{5}{|c|}{ a) From the atmosphere } \\
\hline & $\begin{array}{c}\text { Amount of } \\
\text { precipitation } \\
10^{13} \text { ton } / y\end{array}$ & \multicolumn{2}{|c|}{\begin{tabular}{lc}
\multicolumn{2}{c}{ Concentration in ppt. } \\
Sulfate & Excess sulfate \\
ppm & ppm
\end{tabular}} & $\begin{array}{c}\text { Excess sulfate } \\
\text { deposition } \\
10^{6} \text { ton } / y\end{array}$ \\
\hline Industrial area & 2 & 2.6 & 2.2 & 44 \\
\hline Undeveloped area & 8 & 1.5 & 1.1 & 88 \\
\hline Sea & 30 & 1.0 & 0.2 & 60 \\
\hline Total & 40 & & & 192 \\
\hline \multicolumn{5}{|c|}{ b) To the atmosphere by combustion ${ }^{1)}$} \\
\hline & \multicolumn{4}{|c|}{$\begin{array}{c}\text { Sulfur as sulfate } \\
10^{6} \text { ton } / y\end{array}$} \\
\hline Coal & \multicolumn{4}{|c|}{114} \\
\hline Petroleum & \multicolumn{4}{|c|}{57} \\
\hline Smelting $(\mathrm{Zn}, \mathrm{Pb}$, & \multicolumn{4}{|l|}{ and $\mathrm{Ni}$ ) } \\
\hline $\begin{array}{l}\text { Total } \\
\text { (Wooden fuels }\end{array}$ & \multicolumn{4}{|c|}{$\overline{195}$} \\
\hline
\end{tabular}

1) Estimated in the 1964 level on the same basis as MAGILL et al. (1956)

the snow which was produced from the convective cloud, the good correlations of excess sulfate with ${ }^{210} \mathrm{~Pb}$ and $\beta$ activity reveal that the excess sulfate in rain over the 
ocean is of land origin and is supplied from the upper atmosphere.

JUNGE (1960) estimated the budget of sulfur compounds in the atmosphere and JUNGE (1963) postulated that the chief source of the atmospheric sulfur as the hydrogen sulfide from the decomposition of organic matter and from the reduction of sulfate in the tidal area of the coast. However, there is no evidence for the generation of enormous amounts of hydrogen sulfide in the coastal area or in the ocean. In his calculation, the amount of excess sulfate in rain is much larger than that of the industrial sulfur emitted to the atmosphere. I think that he has overestimated the excess sulfate. Unfortunately, we can not exactly estimate the excess sulfate at present, because our data on sulfur in precipitation are of the rain over mid-latitudes of the northern hemisphere where industry is the most active. Table 4 shows the revised budget of sulfur in the atmosphere by MIYAKE and TsunOGaI (1965), where the amount of excess sulfur in rain is balanced by that of sulfur emitted by industrial activity. It can be concluded that most of the excess sulfur in rain originates in the anthropogenic sulfur.

\section{ACKNOWLEDGMENT}

I am indebted to Prof. M. NISHIMURA who critically read the manuscript.

\section{REFERENCES}

BLIFFoRd, I. H., LOCKHART, L. B. Jr. and RosENSTOCK, H. B. (1952) On the natural radioactivity in the air. J. Geophys. Res. 57, 499-509.

BURTON, W. M. and STEWART, N. G. (1960) Use of long-lived natural radioactivity as an atmospheric tracer. Nature 186, 584-589.

ERIKSSON, E. (1957) The chemical composition of Hawaiian rainfall. Tellus 9, 509-520.

FEELY, H. W. and SEITZ, H. (1970) Use of lead 210 as a tracer of transport in the stratosphere. J. Geophys. Res. 75, 2885-2894.

Gerhard, E. R. and Johnstone, H. F. (1955) Photochemical oxidation of sulfur dioxide in air. Ind. Eng. Chem. 47, 972-976.

IWASAKI, I., UtSUmi, S., Hagino, K., TARUTANI, T. and OZAWA, T. (1957) Spectrophotometric method for the determination of small amounts of sulfate ions. Bull. Chem. Soc. Japan 30, $847-851$.

JUNGE, C. E. (1960) Sulfur in the atmosphere. J. Geophys. Res. 65, 227-237.

JUNGE, C. E. (1963) Air chemistry and radioactivity. Academic Press, New York and London.

Junge, C. E. and MANSON, J. E. (1961) Stratospheric aerosol studies. J. Geophys. Res. 66, 2163-2182.

JUNGE, C. E. and RYAN, T. G. (1958) Study of the $\mathrm{SO}_{2}$ oxidation in solution and its role in atmospheric chemistry. Quart. J. Roy. Meteorol. Soc. 84, 46-55.

JUNGE, C. E. and WERBY, R. T. (1958) The concentration of chloride, sodium, potassium, calcium and sulfate in rain water over the United States. J. Meteorol. 15, 417-425.

King, P., Lockhart, L. B., Bans, R. A., Patterson, R. L., Friedman, H. and Blifford, I. H. (1956) $\mathrm{RaD}, \mathrm{RaE}$ and $\mathrm{Po}$ in the atmosphere. Nucleonics 14, 78-84.

LAL, D. (1959) Cosmic ray produced radioisotopes for study the general circulation in the atmosphere. Indian J. Meteorol. Geophys. 10, 147-154. 
Magill, P. L., Holden, F. R. and ACKLey, C., ed. (1956) Air pollution handbook. McGrawHill, New York. II-45.

MeEtham, A. R. (1950) Natural removal of pollution from the atmosphere. Quart. J. Ray. Meteorol. Soc. 76, 359-371.

MIYAKE, Y. and KUBOTA, U. (1966) Pb-210 and Po-210 in meteoric precipitation. Paper presented at autumn meeting of Meteorological Society of Japan. Sapporo, Oct, 1966.

MIYAKE, Y. and TSUNOGAI, S. (1965) Chemical compositions of meteoric precipitation and airborne dust, and their role on the transport of matter through the atmosphere. Paper presented at annual meeting of Geochemical Society of Japan, Tokyo, Oct. 1965.

Murozumi, M., Chow, T. J. and PATterson, C. (1969) Chemical concentrations of pollutant lead aerosols, terrestrial dusts and sea salts in Greenland and Antarctic snow strata. Geochim. Cosmochim. Acta 33, 1247-1294.

SUGAWARA, K. (1964) Migration of elements through phases of atmosphere and hydrosphere. J. Water and Waste 6, 227-230 and 317-321.

TSUNOGAI, S. and IKEUCHI, K. (1968) Ammonia in the atmosphere. Geochem. J. 2, 157-166.

WeBER, E. (1970) Contribution to the residence time of sulfur dioxide in a polluted area. J. Geophys. Res. 75, 2909-2914.

WEST, P. W. and GAEKE, G. C. (1956) Fixation of sulfur dioxide as disulfitomercurate (II) and subsequent colorimetric estimation. Anal. Chem. 28, 1816-1819. 